\title{
Effect of Radioactive lodine Treatment on Saliva Rate in the Early Post-treatment Period
}

\author{
Taner Demirci ${ }^{1}$, Ceyhun Varim ${ }^{2}$, Ayse Demirci ${ }^{3}$, Mahmut Apaydin $^{4}$, illknur Öztürk Uysal ${ }^{4}$ and Mustafa Ozbek ${ }^{4}$ \\ ${ }^{1}$ Department of Endocrinology and Metabolism, Sakarya University Research and Education Hospital, Sakarya, Turkey \\ ${ }^{2}$ Department of Internal Medicine, Faculty of Medicine, Sakarya University, Sakarya, Turkey \\ ${ }^{3}$ Department of Medical Oncology, Faculty of Medicine, Sakarya University, Sakarya, Turkey \\ ${ }^{4}$ Department of Endocrinology and Metabolism, Diskapi Teaching and Research Hospital, Ankara, Turkey
}

\begin{abstract}
Objective: To investigate the effects of radioactive iodine therapy $\left({ }^{131} I\right)$ on saliva production rate in the early post-treatment period. Study Design: Descriptive, analytical study.

Place and Duration of Study: Department of Endocrinology, Ankara Diskapi Yildirim Beyazit Research and Education Hospital, Ankara, Turkey from January to December 2017.

Methodology: A total of 40 patients, who received radioactive iodine therapy after total thyroidectomy, were included in the study. Stimulated and unstimulated saliva levels were measured before and after treatment, using a scaled and sterile plastic tube.

Results: The study group was comprised of three males (7.5\%) and 37 females (92.5\%) with a mean age of $44.15 \pm 10.2$ years (range 26-66 years). The median values of all non-stimulated saliva before and after RAl treatment were 2.0 ml / minute (1.13-2.88) and $2.0 \mathrm{ml} /$ minute (1.63-4.00), respectively; and the difference was not statistically significant $(p=0.11)$. Similarly, there were no statistically significant differences in the median values of stimulated saliva before and after RAl treatment (median=7.0 $\mathrm{ml} / \mathrm{min}$ and $7.5 \mathrm{ml} / \mathrm{dk}$, respectively; $\mathrm{p}=0.88$ ).
\end{abstract}

Conclusion: Radioactive iodine treatment did not cause sialadenitis and did not affect the saliva production rates in the early posttreatment period.

Key Words: Radioactive iodine, Stimulated saliva, Unstimulated saliva.

How to cite this article: Demirci T, Varim C, Demirci A, Apaydin M, Uysal ?Ö, Ozbek M. Effect of Radioactive lodine Treatment on Saliva Rate in the Early Post-treatment Period. J Coll Physicians Surg Pak 2020; 30(05):490-492. DOI: https://doi.org/10.29271/jcpsp.2020.05.490.

\section{INTRODUCTION}

The glands responsible for saliva production have the ability to selectively concentrate iodine. This feature renders the salivary glands more vulnerable to radiation during the process of radioactive iodine treatment (RIT). ${ }^{1,2}$ Therefore, there may be a reduction in the amount of saliva associated with RIT.1,3,4

The standard treatment of differentiated thyroid cancer is total thyroidectomy, followed by ablation of the remaining residual thyroid tissue with high dose radioactive iodine $\left(\mathrm{RAI}^{131} \mathrm{I}\right) .{ }^{5}$ Sialadenitis is the most common complication after RIT. ${ }^{6}$ While painful swelling of the salivary glands is observed in the early period, it usually causes xerostomia, which is characterised by a decrease in the amount of saliva in a chronic process. ${ }^{4-8}$ Thyroid hormone also has an effect on saliva functions and the level of these hormones fluctuates during the RIT treatment process. In the literature, we did not find a study showing saliva functions at the earliest period, when the RAl effect was high but thyroid hormone levels were normal.

Correspondence to: Dr. Ceyhun Varim, Department of Internal Medicine, Medicine Faculty, Sakarya University, Sakarya, Turkey

E-mail: ceyhunvarim@yahoo.com

Received: January 17, 2020; Revised: March 26, 2020; Accepted: May 17, 2020

DOI: https://doi.org/10.29271/jcpsp.2020.05.490
The aim of this study was to quantify the amount of saliva after RIT and to determine changes, if any, in the early post-RAl period.

\section{METHODOLOGY}

It was a descriptive study carried out between January to December 2017. Forty patients with differentiated thyroid cancer, who had undergone total thyroidectomy accompanied by adjuvant RIT, were enrolled this study. Patients with systemic disease that would affect salivary functions, such as some rheumatologic diseases, were excluded. All patients were questioned about smoking and medication (such as some parasympatholytics) that may affect salivary functions. In addition, patients who had previously received radiotherapy to the head and neck were excluded.

All patients were called to the outpatient unit for saliva collection test, while euthyroid (serum TSH and free T4 in the normal laboratory reference range) before and after RIT treatment. During the RIT treatment period, patients are hypothyroid and the time it takes for them to become euthyroid varies. Hence, after RIT, an average of 4 to 8 weeks was allowed for repeat testing. The purpose of choosing this period is that it is a period in which the RIT effect is high and the thyroid hormone effect is low on the salivary glands. Various methods for collecting saliva have been reported. These methods were compared in terms of validity. ${ }^{9}$ In this study, saliva collection technique in accordance with these methods. Both non-stimulated and stimulated saliva collection methods were used. Both non-stimulated and stimulated methods were 
applied in the same session and 60 minutes apart. Saliva collection time was three minutes, and the average time was used for comparison. In this study, the drainage method was preferred as briefly described below.

One hour before the test, the patients were asked not to eat or drink anything other than water and advised to rinse their mouths several times with distilled water. The test was started after rinsing the mouth. They were asked not to swallow the saliva accumulated in the mouth during the test. During the following 3-minute test, the patients were asked to drain the saliva accumulated in the mouth into a scaled and sterile plastic tube. After the end of the test, because of the pure saliva was very foamy, a certain amount of saline (about 3 milliliters per plastic tube) was added to the scale test tube. The volume was calculated after subtracting the amount of saline added. The same test was carried out with tasteless stimulating gum. After rinsing the mouth, they were asked to chew the gum for at least one minute (60-70/min), after which the saliva was collected. The next steps proceed as described above in the unstimulated whole saliva test.

Statistical analyses were performed using the SPSS software version 22. Descriptive analyses were presented using medians and interquartile range (IQR) for the variables that do not show normal distribution. The qualitative variables were expressed as frequencies along with their percentages. The variables were investigated using visual (histograms, probability plots) and analytical methods (Kolmogorov-Simirnov/Shapiro-Wilk's test) to determine whether or not they are normally distributed. Moreover, descriptive analyses were presented. Since the saliva amount measurements were not normally distributed, nonparametric tests were conducted to compare these parameters. The Wilcoxon test was used to compare the change in saliva amount measurements between pre-and post-RIT. A p-value of less than 0.05 was considered to show a statistically significant result. The study was approved by the Institutional Ethics Committee and all patients submitted an approved informed consent form.

\section{RESULTS}

The study group was comprised of three males (7.5\%) and 37 females $(92.5 \%)$ with a mean age of $44.1 \pm 10.2$ years. None was smoke or used any systemic drug or medicine. Total thyroidectomy had been performed in all patients; 35 patients had papillary carcinoma and five patients had follicular carcinoma. Six patients underwent $150 \mathrm{mCi}$ radioactive iodine therapy due to regional lymph node metastasis. The remaining 34 patients received $100 \mathrm{mCi}$ treatment. The descriptive statistics are summarised in Table I.

All patients were questioned before and after the test for complaints such as dry mouth and swelling of the salivary gland. None of the patients responded positively. When the median values of all non-stimulated saliva measurements before and after RAI treatment were compared, there was no statistically significant difference $(p=0.11)$. Similarly, there were no statistically significant differences in the median values of stimulated saliva before and after RAI treatment $(p=0.88)$. These findings are summarised in Table II. Since the distribution was disproportionate, no comparison was made according to the RAl dose.

\section{DISCUSSION}

Radioactive ${ }^{131}$ treatment may cause deterioration of salivary gland function by $42.9 \%$ in the first year after treatment. ${ }^{10}$ Sialadenitis is the most common complication after RAI treatment. ${ }^{6}$ In the early period after RAl treatment, it is characterised by painful swelling and is usually bilateral. Parotid glands are more affected. ${ }^{7,11,12}$ In our study, all patients were questioned and examined, but no early siala denitis was detected. This may be due to the low treatment dose or the small number of patients.

Table I: Descriptive analysis of baseline characteristics.

\begin{tabular}{|l|c|c|}
\hline & $\begin{array}{c}\text { Number of } \\
\text { patients (\%) }\end{array}$ & Total (n) \\
\hline Age & & 40 \\
Mean & & 44.15 \\
Median & & 43.50 \\
Min-Max & $26-66$ \\
\hline Sex & $37(92.5)$ & \\
Female & $3(7.5)$ & \\
Male & $35(87.5)$ & \\
\hline Histological type & $5(12.5)$ & \\
Papillary thyroid cancer & & \\
Follicular thyroid cancer & $34(85)$ & \\
\hline Radioactive iodine dose & $6(15)$ & \\
100 mCi & & \\
150 mCi & & \\
\hline mCi: Milicurie & & \\
\hline
\end{tabular}

Table II: Summary of changes in saliva measurements before and aftertreatment.

\begin{tabular}{|c|c|c|c|}
\hline & Median (IQR) & Min-Max & $\mathbf{p}$ \\
\hline Pre-treatment unstimulated saliva (ml) & $\begin{array}{c}2.00 \\
(1.13-2.88)\end{array}$ & $0.5-6$ & \multirow{2}{*}{0.11} \\
\hline Post-treatment unstimulated saliva (ml) & $\begin{array}{c}2.00 \\
(1.63-4.00)\end{array}$ & $0.5-6$ & \\
\hline Pre-treatment stimulated saliva (ml) & $\begin{array}{c}7.00 \\
(5.00-10.00)\end{array}$ & $2.5-17$ & \multirow{2}{*}{0.88} \\
\hline Post-treatment stimulated saliva (ml) & $\begin{array}{c}7.50 \\
(5.00-10.00)\end{array}$ & $1.5-20$ & \\
\hline
\end{tabular}

The daily saliva produced by a healthy adult is $1-1.5 \mathrm{ml} / \mathrm{min} .{ }^{13} \mathrm{The}$ majority of this is produced by the submandibular salivary glands under basal conditions. Under stimulation, the parotid glands increase the amount of saliva. ${ }^{1,14,15}$ In the current study, basal salivary functions were evaluated by non-stimulated salivation, while parotid gland functions were evaluated indirectly by stimulated salivation. In one study, the function of the parotid glands in patients receiving RAI was evaluated directly by introducing a catheter into the Stenson's duct. In this study, the doses of RAI administered were reported to be $70,170,270$ and $870 \mathrm{mCi}$. The assessment was designed to be before and one week after RAl treatment. Although the saliva rate decreased significantly as the dose increased, total saliva amount did not fall below normal in any treatment group. ${ }^{16}$ In the present study, a similar number of patients were present, and post-treatment evaluation was performed a little later in our study to control for the possible effects of hypothyroidism. Nevertheless, the results seem similar.

Hypothyroidism and hyperthyroidism may both affect salivary 
functions. ${ }^{15,17}$ In order to increase the effect of iodine given for therapeutic purposes, patients are asked to become hypothyroid. In the current study, the authors waited for the euthyroid state in the post-treatment period to evaluate and reduce the impact of this condition.

There are few limitations in the present study. First, saliva composition was not examined. Second, the number of patients was limited, and treatment dose diversity was low. This limits the generalise ability of the comments in terms of the results.

\section{CONCLUSION}

There was no reduction in the amount of saliva in the euthyroid period of early post-treatment. In addition, there were no clinical signs or symptoms compatible with early sialadenitis. In summary, frequently-used doses of ablation and therapy at 100-150 mci can be considered safe for salivary functions in the early period.

\section{ETHICALAPPROVAL:}

The study was approved by Ankara Diskapi Research and Education Hospital Ethics Committee (20.01.2014-13/07).

\section{PATIENTS' CONSENT:}

All patients submitted an approved informed consent form.

\section{CONFLICT OF INTEREST:}

There is no potential conflict of interest relevant to this article.

\section{AUTHORS' CONTRIBUTION:}

TD: Data gathering, idea owner of this study and statistical analysis.

CV: Writing, submitting manuscript, preparing tables and references.

$A D:$ Study design.

MA: Data gathering and idea owner of this study.

IOU: Data gathering.

MO: Editing and approval of final draft.

\section{REFERENCES}

1. Newkirk KA, Ringel MD, Wartofsky L, Burman KD. The role of radioactive iodine in salivary gland dysfunction. Ear Nose Throat J 2000; 79(6):460-8.

2. Hesselink ENK, Brouwers AH, de Jong JR, van der HorstSchrivers ANA, Coppes RP, Lefrandt JD, et al. Effects of radioiodine treatment on salivary gland function in patients with differentiated thyroid carcinoma: A prospective study. J Nucl Med 2016; 57(11): 1685-91.
3. Xie J, Wang G, Zuo S, Chen Q, Ma C. Amifostine for salivary glands in high-dose radioactive iodine treated differentiated thyroid cancer. Cochrane Database Syst Rev 2009; 2009(4):CD007956.

4. Wu J-Q, Feng H-J, Ouyang W, Sun Y-G, Chen P, Wang J, et al. Systematic evaluation of salivary gland damage following I-131 therapy in differentiated thyroid cancer patients by quantitative scintigraphy and clinical follow-up. Nucl Med Commun 2015; 36(8): 819-26.

5. Pacini F, Castagna MG, Brilli L, Pentheroudakis G. Thyroid cancer: ESMO clinical practice guidelines for diagnosis, treatment and follow-up. Ann Oncol 2010; 23(Suppl 7): 214-19.

6. Mandel SJ, Mandel L. Radioactive Iodine and the salivary glands. Thyroid 2003; 13(3): 265-71.

7. Daniel FI, Lima LD, Grando LJ, Castro R, Cordeiro EAK, et al. Salivary evaluation in radioactive $1^{131}$ treated patients with thyroid carcinoma. Acta Odontol Scand 2018; 76(2); 148-52.

8. Dawes C. How much saliva is enough for avoidance of xerostomia? Caries Res 2004; 38(3):236-40.

9. Navazesh M, Christensen C M A. Comparison of whole mouth resting and stimulated salivary measurement procedures. J Dent Res 1982; 61(10):1158-62.

10. Alexander C, Bader JB, Schaefer A, Finke C, Kirsch CM. Intermediate and long-term side effects of high-dose radioiodine therapy for thyroid carcinoma. J Nucl Med 1998; 39(9): 1551-4.

11. Van Nostrand D, Neutze J, Atkins F. Side effects of "Rational Dose" iodine-131 therapy for metastatic well-differentiated thyroid carcinoma. J Nucl Med 1986; 27(10):1519-27.

12. Upadhyaya A, Meng Z, Wang P, Zhang G, Jia Q, Tan J, et al. Effects of first radioiodine ablation on functions of salivary glands in patients with differentiated thyroid cancer. Medicine (Baltimore) 2017; 96(25):e7164.

13. Humphrey SP, Williamson RT. A review of saliva: Normal composition, flow, and function. J Prosthet Dent 2001; 85(2): 162-9.

14. Eliasson L, Carlén A. An update on minor salivary gland secretions. Eur J Oral Sci 2010; 118(5):435-42.

15. Ford H, Johnson L, Purdie G, Feek C. Effects of hyperthyroidism and radioactive iodine given to ablate the thyroid on the composition of whole stimulated saliva. Clin Endocrinol (Oxf) 1997; 46(2):189-93.

16. Maier $\mathrm{H}$, Bihl $\mathrm{H}$. Effect of radioactive iodine therapy on parotid gland function. Acta Otolaryngol 1987; 103(3-4):318-24.

17. Agha Hosseini F, Shirzad N, Moosavi MS. Evaluation of xerostomia and salivary flow rate in Hashimoto's thyroiditis. Med Oral Patol Oral Cir Bucal 2016; 21(1):e1-5. 